\title{
Fall in pulmonary vascular resistance in patients awaiting heart transplantation
}

\author{
S C D Grant, R D Levy, N H Brooks
}

\footnotetext{
Department of Cardiology,

Wythenshawe Hospital, Manchester S C D Grant R D Levy

N H Brooks

Correspondence to: Dr S C D Grant, Department of Cardiology, Wythenshawe Hospital, Southmoor Road, Manchester M23 9LT.

Accepted for publication 21 April 1992.
}

\begin{abstract}
Background-Raised pulmonary vascular resistance is associated with decreased survival after orthotopic heart transplantation and patients with this risk factor are usually denied transplantation. In a proportion of cases raised pulmonary vascular resistance may fall with time and medical treatment.

Methods-Seven patients with high pulmonary vascular resistance (range 3.9-6.6 Wood units) at initial assessment for cardiac transplantation were restudied by right heart catheterisation after a period of seven to 17 months.

Results-In five of the seven patients the pulmonary vascular resistance had fallen, allowing orthotopic heart transplantation to be performed in four. In one patient the resistance was static and in one it had risen. The mean fall in pulmonary vascular resistance for the group was (mean (SD)) $2 \cdot 6(2 \cdot 7)$ Wood units, p $<0.05$.

Conclusion-Patients who have been denied transplantation on the basis of their raised pulmonary vascular resistance should be reassessed after four to six months if they remain otherwise clinically suitable.
\end{abstract}

\section{(Br Heart J 1992;68:365-8)}

Patients with a raised pulmonary vascular resistance are generally regarded as unsuitable for orthotopic cardiac transplantation because of the high risk of perioperative death from right ventricular failure, ${ }^{12}$ and reduced longterm survival. ${ }^{3}$ It has recently been reported that a high pulmonary vascular resistance acutely unresponsive to intravenous vasodilators or high concentrations of inspired oxygen (so called fixed raised pulmonary vascular resistance) can fall with prolonged intensive medical treatment. ${ }^{4}$

\section{Patients and methods}

Seven patients clinically suitable for heart transplantation were studied. Six had coronary artery disease and one had dilated cardiomyopathy. All were men aged between 21 and 60 .

Table 1 shows details of the patients and their medication. No patient had had an episode of myocardial infarction or cardiac decompensation less than five months before initial assessment. Only minor dose adjustments occurred during this time and the medication remained constant between the assessments.

The patients were assessed by right heart catheterisation on two occasions (table 2). The right heart was catheterised by either the brachial or femoral route with either a $7 \mathrm{FG}$ Swan Ganz thermodilution balloon catheter (Viggo Spectramed) or a 7FG multipurpose catheter (Cordis). Mean pulmonary artery and pulmonary capillary wedge pressure were measured electronically. Cardiac output was assessed either by thermodilution with a Spectramed cardiac output computer or by estimation of the oxygen uptake with a PK Morgan respiratory analyser and calculation from the arterial and pulmonary artery oxygen saturations by the Fick prirciple (table 2). When the thermodilution method was used an average from a minimum of three readings with an agreement of $5 \%$ or better was used.

Where the response to intravenous vasodilator was assessed, this was done by infusion of sodium nitroprusside in four cases and isosorbide dinitrate in one into a peripheral vein (table 2). Infusion was continued in increasing doses until a satisfactory decrease in pulmonary vascular resistance was noticed, or an arterial systolic blood pressure of $80 \mathrm{~mm} \mathrm{Hg}$ was reached, or the patient became symptomatically hypotensive.

The difference in pulmonary vascular resistance between assessments was analysed by paired Student's $t$ test.

\section{Results}

In five of the seven patients the pulmonary vascular resistance had decreased to less than 4 Wood units, and four have undergone standard orthotopic transplantation; one remains on the waiting list. In one patient the pulmonary vascular resistance had increased and in the other it had remained static. Table 2 shows details of the findings at right heart catheterisation. The mean resistance fell from 5.5 to 2.9 ; fall in resistance was mean (SD) $2 \cdot 6(2 \cdot 7)$, $\mathrm{p}<0.05$.

\section{Discussion}

Orthotopic heart transplantation in patients with pulmonary hypertension is associated with an increased risk of perioperative death, principally from right heart failure early after operation. ${ }^{12}$ It is also associated with reduced long-term survival. ${ }^{3}$

Pulmonary artery systolic pressure, trans- 
Table 1 Patient details and total doses of drugs ( $m g /$ day)

\begin{tabular}{|c|c|c|c|c|c|c|c|}
\hline Patient No: & 1 & 2 & 3 & 4 & 5 & 6 & 7 \\
\hline $\begin{array}{l}\text { Age (y) } \\
\text { Aetiology }\end{array}$ & $\begin{array}{l}53 \\
\text { CAD }\end{array}$ & $\begin{array}{l}21 \\
\text { IDC }\end{array}$ & $\begin{array}{c}49 \\
\text { CAD }\end{array}$ & $\begin{array}{l}54 \\
\text { CAD }\end{array}$ & $\begin{array}{l}49 \\
\mathrm{CAD}\end{array}$ & $\begin{array}{c}55 \\
\text { CAD }\end{array}$ & $\begin{array}{l}60 \\
\mathrm{CAD}\end{array}$ \\
\hline $\begin{array}{l}\text { Medication: } \\
\text { Captopril } \\
\text { Enalapril } \\
\text { Frusemide } \\
\text { Digoxin } \\
\text { Nitrate } \\
\text { Anticoagulant } \\
\text { Other }\end{array}$ & $\begin{array}{l}-\overline{5} \\
80 \\
0 \cdot 125 \\
80 \\
\text { Yes }\end{array}$ & $\begin{array}{l}37 \cdot 5 \\
160 \\
0 \cdot 25 \\
\overline{Y e s}^{2}\end{array}$ & $\begin{array}{l}\frac{37 \cdot 5}{120} \\
\overline{120} \\
\text { No } \\
\text { Xamoterol } \\
\text { Amiodarone }\end{array}$ & $\begin{array}{l}\overline{10} \\
80 \\
\overline{-} \\
\overline{\text { No}} \\
\text { Metolazone } \\
\text { Aspirin } \\
\text { Diazepam }\end{array}$ & $\begin{array}{l}37 \cdot 5 \\
\overline{80} \\
\overline{-} \\
\text { No } \\
\text { Amiloride } \\
\text { Xamoterol } \\
\text { Cimetidine }\end{array}$ & $\begin{array}{l}\frac{37 \cdot 5}{160} \\
\frac{-}{40} \\
\text { No } \\
\text { Prochlorperazine } \\
\text { Allopurinol }\end{array}$ & $\begin{array}{l}\frac{75}{40} \\
0 \cdot 25 / 0 \cdot 125 \\
\overline{Y e s}\end{array}$ \\
\hline
\end{tabular}

CAD, coronary artery disease; IDC, idiopathic dilated cardiomyopathy.

pulmonary gradient (mean pulmonary artery pressure - mean pulmonary capillary wedge pressure), pulmonary vascular resistance (transpulmonary gradient/cardiac output) and pulmonary vascular resistance index (pulmonary vascular resistance $\times$ body surface area) have all been used to assess the suitability of patients for heart transplantation. No general agreement exists as to the most useful index.

Measurement of the pulmonary vascular resistance as an indication of the potential right ventricular load is theoretically attractive as it takes into account not only the pressure differences across the pulmonary vasculature but also the cardiac output at the time, and although this pressure flow relation, more correctly termed the pulmonary arterial resistance, is only a component of the impedance to right ventricular ejection, it has been shown to be the dominant factor especially when raised. ${ }^{5}$ Some studies have suggested that pulmonary vascular resistance index, which takes into account body surface area, is a better predictive index of right ventricular failure after operation. ${ }^{6}$ Others have suggested the reverse. ${ }^{7}$ The appeal of these two measures is also their major weakness, however, as estimation of cardiac output may prove unreliable, and errors within the accuracy of the system make a substantial difference to the calculation of pulmonary vascular resistance. Thermodilution (the most convenient method), for example, is known to be inaccurate in the presence of tricuspid regirgitation, ${ }^{8}$ an almost invariable accompaniment of severe congestive cardiac failure. Accordingly the transpulmonary gradient is used as the principal estimate of pulmonary resistance in many centres and there is evidence that it is as reliable as any other measure. ${ }^{39}$

As well as the resting pressure and flow measurements it is possible to manipulate the vascular tone and cardiac output with drugs to examine the patients likely response to transplantation. Traditionally sodium nitroprusside has been used and evidence has suggested that a reversible or partially reversible resistance is predictive of a more favourable outcome than a fixed raised resistance. ${ }^{67}$ It has also been suggested that use of inotropes such as dobutamine or enoximone may be of value, the rationale being that these agents mimic the effect of transplantation by increasing cardiac output by an effect on contractility. Studies on the use of dobutamine and enoximone have suggested that mortality from right heart failure after operation can be improved by the use of exclusion criteria based on these methods. ${ }^{1011}$

A recent retrospective review of the Stanford data $^{7}$ has strongly supported the use of the pulmonary vascular resistance and its manipulation with nitroprusside as the best measurement (although no comparison with the use of inotropes was possible). The findings were that when patients with a resting pulmonary vascular resistance greater or less than 2.5 Wood units were compared, those with the higher pulmonary vascular resistance had a significantly increased postoperative mortality (nearly three times greater). Of these there was a further subdivision into three groups based on the response to nitroprusside: those in whom resistance fell to $<2 \cdot 5$ Wood units but maintained a systolic blood pressure $>85 \mathrm{~mm} \mathrm{Hg}$; those with resistance decreased to $<2.5$ Wood

Table 2 Indices of pulmonary haemodynamic function measured at right heart catheterisation in seven patients (1) initially and (2) at reinvestigation

\begin{tabular}{|c|c|c|c|c|c|c|c|c|}
\hline & \multicolumn{3}{|c|}{ Case 1} & \multicolumn{2}{|c|}{ Case 2} & \multicolumn{3}{|c|}{ Case 3} \\
\hline & 1 & $1+V D$ & 2 & 1 & 2 & 1 & $I+V D$ & 2 \\
\hline INT & & & 13 & & 11 & & & 17 \\
\hline PA $(M)$ & 39 & 40 & 35 & 40 & 20 & 55 & 36 & 23 \\
\hline PCW $(\mathbf{M})$ & 22 & 19 & 30 & 20 & 10 & 36 & 18 & 18 \\
\hline $\mathrm{CO}$ & $2 \cdot 6$ & $3 \cdot 3$ & $3 \cdot 8$ & $4 \cdot 0$ & $5 \cdot 1$ & $3 \cdot 3$ & $4 \cdot 1$ & $5 \cdot 1$ \\
\hline Method & $\mathrm{O}_{2}$ & $\mathrm{O}_{2}$ & TD & TD & $\mathrm{O}_{2}$ & TD & $\mathrm{O}_{2}$ & $\mathrm{O}_{2}$ \\
\hline TPG & $17^{2}$ & $21^{2}$ & 5 & 20 & 10 & 19 & 18 & 5 \\
\hline PVR & 6.5 & 6.4 & $1 \cdot 3$ & $5 \cdot 0$ & $2 \cdot 0$ & $5 \cdot 8$ & $4 \cdot 4$ & $1 \cdot 0$ \\
\hline PVRI & $11 \cdot 7$ & 11.5 & $2 / 3$ & 13 & $5 \cdot 2$ & $11 \cdot 6$ & $8 \cdot 8$ & $2 \cdot 0$ \\
\hline
\end{tabular}

$+\mathrm{VD}$, after intravenous vasodilator (isosorbide dinitrate in case 1, sodium nitroprusside in cases 3, 4, 5, and 6); INT, interval in months between assessments; $\mathrm{PA}(\mathbf{M})$, mean pulmonary artery pressure $(\mathrm{mm} \mathrm{Hg}) ; \mathrm{PCW}(\mathbf{M})$, mean pulmonary capillary wedge pressure $(\mathrm{mm} \mathrm{Hg}) ; \mathrm{CO}$, cardiac output $(1 / \mathrm{min}) ; \mathrm{Method}$, method of measurement of cardiac output; $\mathrm{O}_{2}$, measurement of oxygten pressure $(\mathrm{mm} \mathrm{Hg}) ; \mathrm{CO}$, cardiac output $(1 / \mathrm{min})$; Method, method of measurement of cardiac output; ${ }_{2}$, measurement of oxygten uptake and calculation of CO from Fick principle; TD, thermodilution Swan Ganz catheter; TPG, transpulmonary gradien surface area, Wood units. $\mathrm{m}^{2}$ ) 
units at the expense of systolic hypotension $(<85 \mathrm{~mm} \mathrm{Hg}$ ); and those whose resistance did not fall below 2.5 Wood units. Three month mortality in the three groups was $3.8 \%, 27 \cdot 5 \%$, and $40 \cdot 6 \%$. All of the deaths from right ventricular failure were in the second and third groups.

Our practice has been to measure the pulmonary vascular resistance and if it is raised to give intravenous sodium nitroprusside. We do not use rigid numerical limits although patients with a pulmonary vascular resistance of four to five Wood units or more are evaluated with nitroprusside. Others have published similar practices. $^{3}$

In applying these guidelines it has been stressed that the risk, both immediately and long-term after heart transplantation, rises continuously with increaseing pulmonary resistance and that there is no sharp cut off point. $^{26}$

A recent review advocated reassessment of patients awaiting orthotopic cardiac transplantation every four to six months to ensure that their pulmonary haemodynamics have not deteriorated but did not discuss the possibility of improvement. ${ }^{12}$

A study by Deeb et al compared the use of intravenous amrinone with conventional oral medication (diuretics, digoxin, and captopril) in potential heart transplant recipients with a raised pulmonary vascular resistance or transpulmonary gradient resistant to oxygen and nitroprusside. ${ }^{4} \mathrm{~A}$ fall in resistance and transpulmonary gradient into an acceptable range for orthotopic transplantation was noted in most patients with both treatments (although intravenous amrinone was more effective than the oral regimen).

Our patients received treatment comparable with that of the conventional treatment group described by Deeb et al, ${ }^{4}$ except that inpatient invasive monitoring was not performed and the doses of diuretic we used were smaller $(360 \mathrm{mg}$ frusemide daily plus metolazone in 10 out of 16 of their patients $v 106 \mathrm{mg}$ average dose of frusemide and metolazone in one out of six of our patients): doses of captopril were similar. The cases we describe had been stable for five to 12 months before initial assessment without further infarction or cardiac decompensation and their medication was stable during this period. No details are given of the pre-existing medication in their study, or of any temporal relation to an acute event. Thus it seems likely that our patients are most comparable with the subgroup of patients in that study's group 2 (conventional treatment) who failed to respond to treatment during the study period (six out of 16). This shows that even in this group of nonresponders improvement is possible over a more prolonged period.

From our findings and those already referred to it is clear that patients initially considered to be unsuitable for orthotopic heart transplantation due to unacceptable or marginally acceptable pulmonary haemodynamics, may improve either with intensive medical treatment or long-term conventional treatment. The possibility of such an improvement should be considered in any patient with a raised pulmonary vascular resistance that is thought likely to compromise a successful transplant.

We therefore recommend that patients who are in a stable condition and who are excluded from transplantation on the basis of their pulmonary vascular resistance should be reassessed after four to six months as their resistance may decline and allow successful transplantation.

We support the view that patients on the waiting list for heart transplantation should have pulmonary haemodynamic foundation reassessed every four to six months. They should also be reassessed in the event of a deterioration in their symptoms as the pulmonary vascular resistance may rise progressively even in the absence of a clearly defined cardiac event.

\section{Addendum}

The five patients whose pulmonary vascular resistance had fallen have now been transplanted. One of these was an emergency transplant in the setting of an acute deterioration and the patient died in the perioperative period. The other four were successful although two have died subsequently, one of rejection related to poor compliance with his immunosuppressive medication at four months after transplantation, and the other of a bowel lymphoma 15 months after transplantation. Of the two whose resistance did not fall one had died on the waiting list and the other is on the waiting list awaiting a suitable local donor.

\begin{tabular}{|c|c|c|c|c|c|c|c|c|c|c|}
\hline \multicolumn{3}{|c|}{ Case 4} & \multicolumn{3}{|c|}{ Case 5} & \multicolumn{3}{|c|}{ Case 6} & \multicolumn{2}{|c|}{ Case 7} \\
\hline 1 & $1+V D$ & 2 & 1 & $1+V D$ & 2 & 1 & 2 & $2+V D$ & 1 & 2 \\
\hline $\begin{array}{l}48 \\
28 \\
3 \cdot 3 \\
\text { TD } \\
20 \\
6 \cdot 1 \\
12 \cdot 4\end{array}$ & $\begin{array}{c}48 \\
10 \\
4 \cdot 7 \\
\text { TD } \\
38 \\
8 \cdot 1 \\
16 \cdot 5\end{array}$ & $\begin{array}{c}7 \\
42 \\
28 \\
4 \cdot 3 \\
\text { TD } \\
14 \\
3 \cdot 3 \\
6 \cdot 7\end{array}$ & $\begin{array}{l}65 \\
40 \\
3 \cdot 8 \\
\mathrm{O}_{2} \\
25^{2} \\
6 \cdot 6 \\
12 \cdot 5\end{array}$ & $\begin{array}{c}28 \\
10 \\
5 \cdot 5 \\
\mathrm{O}_{2} \\
18 \\
3 \cdot 2 \\
8 \cdot 6\end{array}$ & $\begin{array}{c}10 \\
37 \\
25 \\
5 \cdot 2 \\
\text { TD } \\
12 \\
2 \cdot 2 \\
4 \cdot 3\end{array}$ & $\begin{array}{c}47 \\
30 \\
3 \cdot 6 \\
\text { TD } \\
17 \\
4 \cdot 7 \\
8 \cdot 9\end{array}$ & $\begin{array}{c}45 \\
27 \\
2 \cdot 3 \\
\mathrm{O}_{2} \\
18 \\
7 \cdot 8 \\
14 \cdot 8\end{array}$ & $\begin{array}{c}4 \\
26 \\
8 \\
2 \cdot 6 \\
\mathrm{O}_{2} \\
18 \\
6 \cdot 9 \\
13 \cdot 1\end{array}$ & $\begin{array}{c}38 \\
20 \\
4 \cdot 6 \\
\mathrm{O}^{2} \\
18^{2} \\
3 \cdot 9 \\
8 \cdot 6\end{array}$ & $\begin{array}{c}16 \\
35 \\
20 \\
4 \cdot 2 \\
\text { TD } \\
15 \\
3 \cdot 8 \\
8 \cdot 4\end{array}$ \\
\hline
\end{tabular}


1 Griepp RB, Stinson EB, Dong E, Clark DA, Shumway NE. Determinants of operative risk in human heart transplanDeterminants of operative risk in

2 Kirklin JK, Naftel DC, McGriffin DC, et al. Analysis of morbid events and risk factors for death after cardiac morbid events and risk factors for death after

3 Erickson KW, Costanzo-Nordin MR, O'Sullivan EJ, et al. Influence of preoperative transpulmonary gradient on lat mortality after orthotopic heart transplantation. $J$ Hear Transpl 1990;9:526-37.

4 Deeb GM, Bolling SF, Guynn TP, Nicklas JM. Amrinone versus conventional therapy in pulmonary hypertensive patients awaiting cardiac transplantation. Ann Thorac Surg 1989;48:665-9.

5 Harris $\mathrm{P}$, Heath $\mathrm{D}$. The human pulmonary circulation. 3rd ed. London: Churchill Livingstone, 1986:134.

6 Addonizio LJ, Gersony WM, Robbins RC, et al. Elevated pulmonary vascular resistance and cardiac transplantation. Circulation 1987;76(suppl V):52-5.

7 Costard-Jackie A, Fowler MB. Influence of preoperative pulmonary artery pressure on mortality after heart transplantation: testing of potential reversibility of pulmonary hypertension with nitroprusside is useful in defining a high risk group. J Am Coll Cardiol 1992;19:48-54.

8 Grossman W. Cardiac catheterisation and angiography. 3rd ed. Philadelphia: Lea and Febiger, 1986:116.

9 Kormos RL Thompson M Hardesty RL, et al. Utility of ( preoperative right heart catheterisation data as a predictor Transpl 1986;5:391. Transpl 1986;5:391.

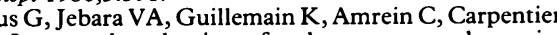
$\mathrm{AF}$. Improved evaluation of pulmonary vascular resistance prior to heart transplantation. Transpl Proc 1989 21:2559-61.

11 [Pornin M, Allal J, Bouton S, et al. Enoximone in the hemodynamic evaluation before heart transplantation. A new test]. Arch Mal Coeur 1990;83:95-101.

12 Schofield PM. Indications for cardiac transplantation. $\mathrm{Br}$ Heart J 1991;65:55-6. 